\title{
Variceal band ligation and its outcome: a single Tertiary Care Centre study.
}

1. MBBS, FCPS

Senior Registrar Gastroenterology Lahore General Hospital, Lahore.

2. MBBS, MCPS (Med), FCPS (Gl)

Associate Professor

Gastroenterology

$\mathrm{NMU}$, Multan

3. MBBS, FCPS

Assistant Professor Gastroenterology

Lahore General Hospital, Lahore.

4. MBBS, FCPS

Senior Registrar Gastroenterology Lahore General Hospital, Lahore.

5. MBBS, MCPS (Med), FCPS (GI)

Associate Professor

Gastroenterology

Lahore General Hospital, Lahore.

6. MBBS, MCPS (Med), FCPS (GI)

Associate Professor

Gastroenterology

Gujranwala Medical College,

Gujranwala.

\section{Correspondence Address:}

Dr. Muhammad Asif Gul

Department of Gastroenterology

NMU, Multan.

asifgul141@gmail.com

Article received on:

04/04/2019

Accepted for publication

$15 / 08 / 2020$
Hafiz Hafeez Anjum¹, Muhammad Asif Gul², Shafqat Rasool ${ }^{3}$, Muhammad Usman Khan ${ }^{4}$, Akif Dilshad ${ }^{5}$, Asif Mehmood ${ }^{6}$

ABSTRACT... Objectives: To determine the frequency of complications after esophageal variceal band ligation in patients of decompensated chronic liver disease. Study Design: Descriptive Case study Setting: Department of Gastroenterology Lahore General Hospital, Lahore. Period: June 2015 to June 2016. Material \& Methods: In the present study, the cases of both genders and age more than 20 years having esophageal variceal of any grade on variceal screening esophagogastroduodenoscopy and duration of decompensated liver cirrhosis of at least 6 months or more were included. Esophageal variceal band ligation was performed using a multiband ligation device (Six-shooter, Wilson-Cook Inc., Winston-Salem, NC) and up to 6 bands were placed per session and next session was performed at 2 week intervals until esophageal varices were eradicated, which was defined as a complete disappearance of varices and/or the presence of a varix being too small to be ligated. Results: In this study there were total 720 cases out of which 450 (62.5\%) were males and 270 (37.5\%) females. The mean age of the subjects was $33.504 \pm 4.00$ years, mean duration of cirrhosis was $9.086 \pm 2.54$ months and mean weight was $72.44 \pm 13.78 \mathrm{Kg}$. Ulcer bleed was seen in $6.9 \%$ patients and esophageal strictures was seen in $2.5 \%$ patients. Conclusion: Complications of esophageal variceal band ligation are not that common and amongst them ulcer bleed is the salient one. Both ulcer bleed and esophageal stricture are significantly associated with varices more than 2 .

Key words: $\quad$ Band Ligation, Esophageal Strictures, Ulcer Bleed.

Article Citation: Anjum HH, Gul MA, Rasool S, Khan MU, Dilshad A, Mehmood A. Variceal band ligation and its outcome: A single tertiary care centre study. Professional Med J 2020; 27(11):2453-2457. https://doi.org/10.29309/TPMJ/2020.27.11.4050

\section{INTRODUCTION}

Liver cirrhosis is defined as an irreversible damage and scarring due to ongoing inflammation of the liver parenchyma. There are number of causes leading to this, among them hepatitis $B$ and $C$ are the most common infections and alcoholism as the leading non infectious causes. ${ }^{1,2}$

It can result in various complications like portal hypertension, ascites, Gl (gastrointestinal) bleeding, varices, porto pulmonary and porto systemic hypertension, caput medusa, spider angioma, AV malformations, hepatic encephalopathy etc. ${ }^{3-4}$

Portal hypertension is considered among the highly morbid and fatal complication of liver cirrhosis and it results from the combination of increased intrahepatic vascular resistance and increased blood flow through the portal venous system. Portal hypertension causes the development of porto systemic collaterals, among which esophageal and gastric varices are the most relevant. Their rupture can result in variceal hemorrhage, which is one of the most life threatening complication of cirrhosis. ${ }^{5-6}$

Prospective studies have shown that more than $90 \%$ of cirrhotic patients develop esophageal varices sometime in their lifetime and $30 \%$ of these will bleed. When cirrhosis is diagnosed, varices are present in about $30 \%-40 \%$ of compensated patients and $60 \%$ present with ascites. ${ }^{7-8}$ Stigmann et al first introduced the technique of endoscopic band legation. This mechanical method of obliterating variceal with elastic O-ring 
should produce no systemic sequalae. ${ }^{9}$ Studies have been done on variceal banding about the safety and efficacy of the method. Some trials have shown that banding is superior with respect to prevention of recurrences, control of active bleeding and survival. ${ }^{10}$ However, long term follow up have shown variable complications and their prevalence, among them ulcer bleeding and esophageal strictures are salient one.

To determine the frequency of complications after esophageal variceal band ligation in patients of decompensated chronic liver disease.

\section{MATERIAL \& METHODS}

This was a descriptive case study carried out at Department of Gastroenterology Lahore General Hospital, Lahore during June 2015 to June 2016. The cases were selected via non probability consecutive sampling. In this study a total of 720 patients of both genders and age more than 20 years having esophageal variceal of any grade on variceal screening esophagogastroduodenoscopy and duration of decompensated liver cirrhosis of at least 6 months or more were included. The cases underwent detailed laboratory, radiological and clinical examination to assess for duration of cirrhosis, West Haven criteria to grade for encephalopathy.

Patients with history of gastrointestinal (Gl) bleeding, hepatocellular carcinoma (HCC) on biopsy, pregnancy on ultrasound and history of gastric or duodenal ulcer were excluded. Patients were undergone ligation after an initial screening gastroscopy that was performed to assess the size and appearance of esophageal and gastric varices and to exclude other lesions such as ulcers and tumors. The intravenous administration of 5 to $10 \mathrm{mg}$ of diazepam was used for sedation on individual basis. Esophageal variceal band ligation was performed using a multiband ligation device (Six-shooter, Wilson-Cook Inc., Winston-Salem, $\mathrm{NC})$ and up to 6 bands were placed per session beginning in the distal esophagus just above the gastro esophageal junction. Next session was performed at 2 weeks intervals until esophageal varices were eradicated. Variceal eradication was defined as a complete disappearance of varices and/or the presence of a varix being too small to be ligated $(<5 \mathrm{~mm})$. All patients were followed every month for any history of upper GI bleed and upper $\mathrm{Gl}$ endoscopy was done at 6 months. Data was recorded regarding complications in terms of ulcer bleed and esophageal strictures.

Data was analyzed with statistical analysis program (SPSS version11). Frequency and percentage was computed for qualitative variables and Mean $\pm S D$ was presented for quantitative variables. Effect modifiers were controlled by stratification. Post stratification chi square test was applied $p$ $\leq 0.05$ was considered statistically significant.

\section{RESULTS}

In this study there were total 720 cases out of which $450(62.5 \%)$ were males and 270 (37.5\%) females (Table-I). There were 392 $(54.4 \%)$ of the cases that had varices grade 1-2 (Table-I). The mean age of the subjects was $33.50 \pm 4.00$ years, mean duration of cirrhosis was $9.086 \pm 2.54$ months and mean weight was $72.44 \pm 13.78 \mathrm{Kg}$ (Table-II). Ulcer bleed was seen in $6.9 \%$ patients and esophageal strictures was seen in $2.5 \%$ patients (Figure-I). Stratification of ulcer bleed and esophageal strictures with respect to age groups, gender, BMI, duration of cirrhosis, grade of esophageal varices and West Haven Grade are shown in Table-III.

\begin{tabular}{|c|c|c|}
\hline Gender & No of Patients & \%age \\
\hline Male & 450 & $62.5 \%$ \\
\hline Female & 270 & $37.5 \%$ \\
\hline \multicolumn{3}{|l|}{ Grades } \\
\hline $1-2$ & 392 & $54.4 \%$ \\
\hline$>2$ & 328 & $45.6 \%$ \\
\hline \multicolumn{3}{|c|}{$\begin{array}{l}\text { Table-I. \%age of patients according to gender } \\
\qquad(n=720) .\end{array}$} \\
\hline \multicolumn{2}{|c|}{ Demographics } & Mean $\pm S D$ \\
\hline \multicolumn{2}{|l|}{ Age(years) } & $33.504 \pm 4.00$ \\
\hline \multicolumn{2}{|c|}{ Duration of cirrhosis(months) } & $9.086 \pm 2.54$ \\
\hline \multicolumn{2}{|l|}{ Weight(Kg) } & $72.436 \pm 13.78$ \\
\hline
\end{tabular}




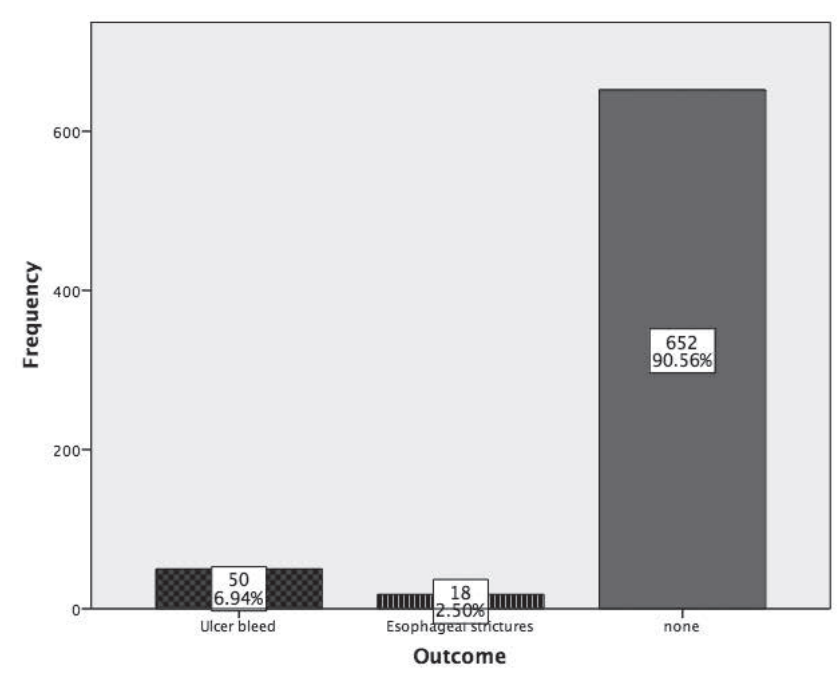

Figure-1. Outcome $(n=720)$.

\begin{tabular}{|c|c|c|c|c|}
\hline \multicolumn{2}{|c|}{ Variables } & \multicolumn{2}{|c|}{ Ulcer Bleed } & \multirow[t]{2}{*}{$\begin{array}{c}\text { P. } \\
\text { Value }\end{array}$} \\
\hline & & \multirow{2}{*}{$\begin{array}{c}\text { Yes } \\
11(8.4 \%)\end{array}$} & \multirow{2}{*}{$\begin{array}{c}\text { No } \\
120(91.6 \%)\end{array}$} & \\
\hline \multirow{2}{*}{ Age } & $18-30$ & & & \multirow{2}{*}{0.470} \\
\hline & $31-40$ & $39(6.6 \%)$ & $550(93.4 \%)$ & \\
\hline \multirow{2}{*}{ Gender } & Male & $37(8.2 \%)$ & $413(91.8 \%)$ & \multirow{2}{*}{0.08} \\
\hline & Female & $13(4.8 \%)$ & $257(95.2 \%)$ & \\
\hline \multirow{3}{*}{ BMI } & $21-25$ & $17(8.3 \%)$ & $188(91.7 \%)$ & \multirow{3}{*}{0.395} \\
\hline & $26-30$ & $20(7.5 \%)$ & $246(92.5 \%)$ & \\
\hline & $>30$ & $13(5.2 \%)$ & $236(94.8 \%)$ & \\
\hline \multirow{2}{*}{$\begin{array}{l}\text { Duration of } \\
\text { cirrhosis }\end{array}$} & $<1$ year & $35(6.7 \%)$ & $485(93.3 \%)$ & \multirow[b]{2}{*}{0.71} \\
\hline & $\begin{array}{l}1 \text { or } \\
\text { more }\end{array}$ & $15(7.5 \%)$ & $185(92.5 \%)$ & \\
\hline \multirow{2}{*}{$\begin{array}{l}\text { Grade of } \\
\text { varices }\end{array}$} & $1-2$ & $17(4.3 \%)$ & $375(95.7 \%)$ & \multirow{2}{*}{0.03} \\
\hline & $>2$ & $33(10.1 \%)$ & $295(89.9 \%)$ & \\
\hline \multirow{2}{*}{$\begin{array}{l}\text { West Haven } \\
\text { grade }\end{array}$} & $1-2$ & $32(7.7 \%)$ & $382(92.3 \%)$ & \multirow{2}{*}{0.33} \\
\hline & $3-4$ & $18(5.9 \%)$ & $288(94.1 \%)$ & \\
\hline & & \multicolumn{2}{|c|}{ Esophageal Strictures } & \\
\hline \multirow{2}{*}{ Age } & $18-30$ & $4(3.1 \%)$ & $127(96.9 \%)$ & \multirow{2}{*}{0.65} \\
\hline & $31-40$ & $14(2.4 \%)$ & $575(97.6 \%)$ & \\
\hline \multirow[b]{2}{*}{ Gender } & Male & $13(2.9 \%)$ & $437(97.1 \%)$ & \multirow{2}{*}{0.39} \\
\hline & Female & $5(1.9 \%)$ & $265(98.1 \%)$ & \\
\hline \multirow{3}{*}{ BMI } & $21-25$ & $6(2.9 \%)$ & 199(97.1\%) & \multirow{3}{*}{0.89} \\
\hline & $26-30$ & $6(2.3 \%)$ & $260(97.7 \%)$ & \\
\hline & $>30$ & $6(2.4 \%)$ & $243(97.6 \%)$ & \\
\hline \multirow{2}{*}{$\begin{array}{l}\text { Duration of } \\
\text { cirrhosis }\end{array}$} & $<1$ year & $13(2.5 \%)$ & $507(97.5 \%)$ & \multirow{2}{*}{1.0} \\
\hline & 1or more & $5(2.5 \%)$ & $195(97.5 \%)$ & \\
\hline \multirow{2}{*}{$\begin{array}{l}\text { Grade of } \\
\text { varices }\end{array}$} & $1-2$ & $4(1.0 \%)$ & $388(99.0 \%)$ & \multirow{2}{*}{0.005} \\
\hline & $>2$ & $14(4.3 \%)$ & $314(95.7 \%)$ & \\
\hline \multirow{2}{*}{$\begin{array}{l}\text { West Haven } \\
\text { grade }\end{array}$} & $1-2$ & $9(2.2 \%)$ & $405(97.8 \%)$ & \multirow{2}{*}{0.51} \\
\hline & $3-4$ & $9(2.9 \%)$ & $297(97.1 \%)$ & \\
\hline
\end{tabular}

Table-III. Outcomes with respect to confounders $(n=720)$.

\section{DISCUSSION}

Upper $\mathrm{Gl}$ bleed is a common presentation and endoscopic variceal ligation (EVL) is commonly practiced now, which was first done by Steigniann in $1986 .{ }^{11}$

The data has shown that ligation fasten the process of variceal obliteration by causing fibrosis and recurrence rates are low for longer periods of follow up. ${ }^{12,13}$ There are no systemic side effects associated with esophageal variceal band ligation as compared to injection sclerotherapy. The major complications of the procedure include discomfort, dysphagia, esophageal strictures, re bleed etc. ${ }^{13}$

In the present study ulcer bleed was seen in $6.9 \%$ patients and esophageal strictures was seen in $2.5 \%$ of the patients, respectively. There results were close to the findings of the study done by Lo et al. ${ }^{14}$ where they did this intervention in 120 cases of esophageal varices and it was found that its was highly efficacious and the only complication observed in 3 cases was ulcer bleeding. ${ }^{14}$

In another study done by Laine et al. ${ }^{15}$ carried out a meta-analysis and compared EVL to sclerotherapy and it was found equally effective in both cases but the re-bleeding was an issue and was seen in more cases with band ligation. ${ }^{15}$

Re bleeding from band ligation of the esophageal varices was also the major complication that was observed in short term follow up in a study done by Shahi $\mathrm{H}$ et al. ${ }^{16}$ According to another study done by Shrestha B et al this was seen in only one $(1.2 \%)$ out of 83 cases. ${ }^{17}$

Sarin et al. $^{18}$ in their study also revealed a highly efficacious outcome in cases with EVL as compared to propranolol, where risk of bleeding was equal in both groups. ${ }^{18}$

In the present study esophageal strictures was seen in $2.5 \%$ patients which were similar to the study done by Stanley et al and seen in $2 \%$ of the cases. ${ }^{19}$

In another study compared EVL with sclerotherapy and both had equal rates of stricture formation 
having less than $5 \%$ of the cases and re bleed was the commonest complication after dysphagia. ${ }^{20}$

In another study carried out by Masci et al. ${ }^{22}$ esophageal stenosis after banding was reported as $2 \%$ whereas its incidence after sclerotherapy ranged between 0 and 33\%; the incidence of bleeding from treatment-induced ulcers was lower with banding in all studies but one. ${ }^{23}$ In a study done by Arasu $S$ et al, there was none of the cases found with stricture after EVL. ${ }^{24}$

\section{CONCLUSION}

Complications of esophageal variceal band ligation are not that common and amongst them ulcer bleed is the salient one. Both ulcer bleed and esophageal stricture are significantly associated with varices more than 2 .

Copyright@ 18 Aug, 2020.

\section{REFERENCES}

1. Scagilone S, Kliethermes S, Cao G, Shoham D, Durazo R. Epidemiology of liver cirrhosis in the United States: A population based study. J Clin Gastroenterol. 2015; 49(8):690-6.

2. Stasi C. Epidemiology of liver cirrhosis. J Clin Exp Hepatol. 2015; 5(3):272.

3. De Franchis R. Expanding consensus in portal hypertension. J Hepatol. 2015; 63:743-52.

4. Garcia-Tsao G, Bosch J. Varices and variceal haemorrhage in cirrhosis: A new view of an old proble. Clin Gastroenterol Hepatol. 2015; 13:2109-17.

5. de Franchis R, Baveno $\mathrm{VI}$ Faculty. Expanding consensus in portal hypertension: Report of the Baveno VI Consensus Workshop: Stratifying risk and individualizing care for portal hypertension. J Hepatol 2015; 63:743.

6. Tetangsco EP, Silva RG, Lerma EV. Portal hypertension: Etiology, evalulation and management. Dis Mon. 2016; 62:411-16.

7. Garcia-Tsao G, Abraldes JG, Berzigotti A, et al. Portal hypertensive bleeding in cirrhosis: Risk stratification, diagnosis, and management: 2016 practice guidance by the American Association for the study of liver diseases. Hepatology 2017; 65:310.
8. Simonetto DA, Liu M, Kamath PS. Portal hypertension and related complications: Diagnosis and management. Thematic Rev Series Gastroenterol Dis. 2019; 94(4):714-26.

9. Steigmann GV, Goff IS, Sun IH, Hruza D, Reveille RM. Endoscopic ligation of esophageal varices. Am J Surg. 1990; 150:21-6.

10. Tripathi D, Stanley AJ, Hayes PC, et al. U.K. Guidelines on the management of variceal haemorrhage in cirrhotic patients. Gut 2015; 64:1680.

11. Haq I, Tripathi D. Recent advances in the management of variceal bleeding. Gastroenterol Report. 2017; 5(2):113-26.

12. Ray G. Long-term outcome of endoscopic variceal band ligation of esophageal varices in patients with chronic liver disease. Indi J Gastroenterol. 2019; 38(1):69-76.

13. De Franchis R, Primignani M. Endoscopic treatments for portal hypertension. Bailliere's Clinical Gastroenterology. 1997; 11: 289-309.

14. Lo G, Lai K, Cheng J. A prospective, randomized trial of sclerotherapy versus ligation in the management of bleeding esophageal varices. Hepatology 1995; 22: 466-71.

15. Laine L, Cook D. Endoscopic ligation compared with sclerotherapy for treatment of esophageal variceal bleeding. Ann Intern Med 1995; 123: 280-7.

16. Shahi $H$, Sarin S. Prevention of first variceal bleed: An appraisal of current therapies. Am J Gastroenterol 1998; 93:2348-58.

17. Shrestha B, Kc S, Chaydhary S, Basnet BK, Mandal AK, Poudyal NS. Outcome of enoscopic variceal band ligation. J Nepal Med Assoc. 2017; 56(206):198-202.

18. Sarin S, Lamba G, Kumar M, et al. Comparison of endoscopic ligation and propranolol for the primary prevention of variceal bleeding. N Engl J Med 1999; 340: 988-93.

19. Stanley AJ, Hayes PC. Portal hypertension and variceal haemorrhage. Lancet 1997; 350: 1235-9.

20. D'Amico G, Pagliaro L, Bosch J. The treatment of portal hypertension: A meta-analytic review. Hepatology 1995; 22:332-54.

21. Laine L, Cook D. Endoscopic ligation compared with sclerotherapy for treatment of esophageal variceal bleeding. A meta-analysis. Ann Intern Med 1995; 123 : 280-7. 
22. Masci E, Norberto L, D'Imperio N, et al. Prospective multicentric randomized trial comparing banding ligation with sclerotherapy of esophageal varices [Abstract]. Ital J Gastroenterol. 1996; 28 (Suppl 2): 170.

23. Stiegmann GV, Goff JS, Michaletz-Onody PA, et al. Endoscopic sclerotherapy as compared with endoscopic ligation for bleeding esophageal varices. N Engl J Med 1992; 326:1527-32.
24. Arasu S, Liaquat H, Suri J, Ehrlich AC, Friedenberg FK. Incidence and risk factors of dysphagia after variceal band ligation. Clin Mol Hepatol. 2019; 25(4):374-80.

\begin{tabular}{|c|l|l|l|}
\hline \multicolumn{3}{|c}{ AUTHORSHIP AND CONTRIBUTION DECLARATION } \\
\hline Sr. \# & \multicolumn{1}{|c|}{ Author(s) Full Name } & \multicolumn{1}{|c|}{ Contribution to the paper } & Author(s) Signature \\
\hline 1 & Hafiz Hafeez Anjum & Data collection. \\
\hline 2 & Muhammad Asif Gul & Drafting of paper. \\
\hline 3 & Shafqat Rasool & Data collection. \\
\hline 5 & Akif Dilshad & Data collection. \\
\hline 6 & Asif Mehmood & Review of paper. \\
\hline
\end{tabular}

